\title{
ANALISIS MORFOMETRI DAN MORFOSTRUKTUR LERENG KEJADIAN LONGSOR DI KECAMATAN BANJARMANGU KABUPATEN BANJARNEGARA
}

\author{
Kuswaji Dwi Priyono dan Priyono \\ Fakultas Geografi Universitas Muhammadiyah Surakarta \\ Jl. A. Yani Pabelan Kartasura Tromol Pos I Surakarta 57102, Telp. (0271) 717417 \\ Psw. 151-153, Fax. (0271) 7155448 \\ E-mail:kuswaji@yahoo.com,drspriyono@yahoo.com
}

\begin{abstract}
Yhe

aims of this research are: (a) to study and classify the landslide hazard level, and (b) to analysis morphometry and morphostructure slope at occurrence slides in the research area. The sampling method applied in this research was stratified sampling, landform units were applied as strata. The sample within strata was determined according the landslide hazard based factor that caused landslides. Analysed of morphometry and morphostructure conducted in described of landform units. The landslide location was mapped by determining landslide point with Global Position System (GPS), and morphometry slope analysis in three images with Digital Elevation Model (DEM) analysis. The results showed that the degree of landslide hazard in the research area could be classified into 9 units landform with 5 landslide hazard level, from very low until very high. At very high landslide hazard existed occurrence landslides at most, whereas at very low landslide hazard existed occurrence at least. From slope morphometry aspect, the point of the most landslide case is in mountain midle slope (11), lower slope (9), and upper slope (5). Flows type, soil fall, and rockfall all happen in lower slope. Landslide types almost (80\%) bappen in lower slope, whereas slump type happen in upper, middle, and lower slope. From slope form aspect, 70\% landslide cases happen in concave slope position and slope classes 3-5 (>9\%). From morphostructure aspect, the research area hasn't difference because of weathering level and litology structure condition which is relatively similar. Concave and aslant slope condition become the concentration point of surface flow water and under surface which are predicted be the most influence factor that cause landslide.
\end{abstract}

Keyword: landslide hazard, morphometry, morphostructure

\section{PENDAHULUAN}

Bencana longsor tanah merupakan salah satu jenis bencana alam yang banyak menimbulkan korban jiwa dan kerugian material yang sangat besar, seperti: rusaknya lahan pertanian, kawasan permukiman, jalan, jembatan, irigasi, dan prasarana fisik lainnya. Bencana longsor tanah yang terjadi pada 4 Januari 2006 di Dusun Gunungraja, Desa Sijeruk, Kecamatan Banjarmangu, Kabupaten Banjarnegara telah menelan korban lebih 100 jiwa dan kerusakan lahan pertanian seluas lebih 4 ha, serta kerusakan sekitar 55\% dari 185 rumah yang dihuni 665 jiwa. Lokasi longsor tersebut terletak di daerah pegunungan vulkanik, yaitu Gunung Pawinihan dengan ketinggian $1.240 \mathrm{~m}$ dpal yang termasuk wilayah Pegunungan Serayu Utara. Gunung Pawinihan merupakan batuan gunungapi Kuarter dengan batuan andesit hiperten-augit yang mengandung hornblende dan basal olivine serta aliran lava dan breksi piroklastik dengan tingkat pelapukan yang tinggi. Lapisan batuan ini mengandung batulem- 
pung, konglomerat, serta tuff dasit yang menjadi pemicu longsoran di samping curah hujan tahunan yang tinggi (3.191 $\mathrm{mm} / \mathrm{th}$ ) dan kemiringan lereng $30^{\circ}-45^{\circ}$.

Potensi kejadian longsoran di kawasan pegunungan di Kabupaten Banjarnegara sangat besar yang memungkinkan terjadi dari tahun ke tahun. Potensi kejadian tersebut telah banyak dilakukan penelitian dan dipublikasikan bahwa Kecamatan Banjarmangu termasuk dalam 14 kecamatan di Kabupaten Banjarnegara yang potensial terjadinya bencana longsoran. Penelitian terdahulu menunjukkan analisis yang sama terhadap faktor-faktor penyebab dan pemicu pada berbagai tipe longsoran yang berbeda, belum menjawab pada titik/lokasi dimana kejadian longsor pada suatu satuan pemetaan yang ada akan terjadi.

Mengacu pada berbagai konsep dan hasil kajian penelitian terdahulu, maka pertanyaan yang muncul adalah: "Bagaimanakah sebaran kejadian longsoran di daerah penelitian?; dan bagaimanakah morfometri dan morfostruktur lereng berpengaruh pada sebaran kejadian longsoran yang ada?". Mempertimbangkan hal-hal tersebut di atas, analisis morfometri dan morfostruktur lereng pada kejadian longsor dapat digunakan untuk usaha pencegahan dan penanggulangan bencana. Potensi terjadinya longsoran ini dapat diminimalkan dengan memberdayakan masyarakat untuk mengenali tipologi lereng yang rawan longsor tanah, gejala awal lereng akan bergerak, serta upaya antisipasi dini yang harus dilakukan. Sistem peringatan dini yang efektif sebaiknya dibuat berdasarkan prediksi, bilamana dan dimana longsor akan terjadi juga tindakan-tindakan yang harus dilakukan pada saat bencana datang.

\section{METODE PENELITIAN}

Penelitian ini diawali dengan pemetaan bentuklahan berdasarkan analisis morfologi/relief, litologi/struktur batuan, dan proses geomorfologi melalui interpretasi citra landsat dibantu peta rupabumi dan peta geologi. Dilanjutkan pengambilan dan pengamatan sampel di lapangan untuk memperoleh data karakteristik lahan. Penilaian tingkat kerawanan longsor dengan skoring seperti yang telah dilakukan oleh Sunarto Goenadi, dkk (2003) dengan perubahan yang telah dilakukan peneliti pada penelitian sebelumnya (2006). Lokasi pengamatan ditentukan berdasarkan peta bentuklahan, kualitas dan karakteristik lahan yang dikaji dalam penelitian ini disajikan pada Tabel 1. Dalam pembe-rian harkat untuk masing-masing parameter diklasifikasikan ke dalam lima klas. Harkat yang paling tinggi (5) adalah yang paling besar pengaruhnya terhadap terjadinya longsoran. Harkat yang paling rendah (1) adalah yang paling kecil pengaruhnya terhadap terjadinya longsoran

Pembobotan disusun atas dasar pemahaman faktor penyebab dan faktor pemicu terjadinya longsoran. Faktor yang menyebabkan terjadinya longsoran adalah gaya gravitasi yang bekerja pada suatu massa tanah dan atau batuan. Di lapangan besarnya pengaruh gaya gravitasi terhadap massa tanah dan atau batuan ditentukan oleh besarnya sudut lereng. Oleh karena itu dalam penilaian tingkat kerawanan longsor, faktor lereng diberikan bobot yang paling tinggi (bobot 10) dibandingkan faktorfaktor lain.

Pemberian bobot pada faktor pemicu, yang dalam hal ini dikelompokkan 
Tabel 1. Pengharkatan dan Pembobotan Parameter yang Mempengaruhi Longsoran

\begin{tabular}{|c|c|c|c|c|c|c|c|c|c|}
\hline \multirow[t]{2}{*}{ No } & \multirow[t]{2}{*}{ Jenis Faktor } & \multirow[t]{2}{*}{ Parameter } & \multirow{2}{*}{$\begin{array}{l}\text { Bobot } \\
\text { (B) }\end{array}$} & \multirow{2}{*}{$\begin{array}{c}\text { Konstanta } \\
(\mathrm{K})\end{array}$} & \multirow[t]{2}{*}{$\mathrm{B} * \mathrm{~K}$} & \multicolumn{2}{|c|}{ Harkat } & \multicolumn{2}{|c|}{$\begin{array}{c}\text { Harkat x Bobot x } \\
\text { Konstanta }\end{array}$} \\
\hline & & & & & & Min & Maks & Min & Maks \\
\hline 1 & Faktor Penyebab & Kemiringan Lereng & 10 & 1 & 10 & 1 & 5 & 10 & 50 \\
\hline 2 & \multirow{2}{*}{$\begin{array}{l}\text { Faktor Pemicu } \\
\text { (Dinamik) }\end{array}$} & Hujan & 8 & 0,7 & 5,6 & 1 & 5 & 5,6 & 28 \\
\hline 3 & & Penggunaan Lahan & 8 & 0,3 & 2,4 & 1 & 5 & 2,4 & 12 \\
\hline 4 & \multirow{4}{*}{$\begin{array}{l}\text { Faktor Pemicu } \\
\text { (Statis) }\end{array}$} & Pelapukan Batuan & 6 & 0,7 & 4,2 & 1 & 5 & 4,2 & 21 \\
\hline 5 & & Kedalaman Tanah & 6 & 0,15 & 0,9 & 1 & 5 & 0,9 & 4,5 \\
\hline 6 & & Struktur Perlapisan & 6 & 0,09 & 0,54 & 1 & 5 & 0,54 & 2,7 \\
\hline 7 & & Tekstur & 6 & 0,06 & 0,36 & 1 & 5 & 0,36 & 1,8 \\
\hline & & & & & & & & 24 & 120 \\
\hline
\end{tabular}

Sumber : Sunarto Goenadi, dkk. (2003) dengan perubahan Kuswaji (2006)

menjadi 2 yaitu faktor yang bersifat statik dan faktor yang bersifat dinamik. Faktor yang dinamik diberi bobot yang lebih tinggi dikarenakan kejadian longsoran selalu dipicu oleh adanya perubahan gaya/energi akibat perubahan faktor yang bersifat dinamik. Termasuk di dalam kategori faktor yang dinamik ini adalah hujan dan penggunaan lahan. Faktor hujan mempunyai bobot yang lebih tinggi $(5,6)$ dibandingkan dengan penggunaan lahan dikarenakan hujan $(2,4)$ dapat mempengaruhi perubahan besar beban massa batuan dan atau tanah secara relatif lebih cepat/dramatik dibandingkan dengan penggunaan lahan.

Dalam penelitian ini, kemiringan lereng datar/landai (harkat 1) hingga terjal/ sangat terjal (harkat 5); penggunaan lahan di dasar lembah (1) hingga sawah (5); tingkat pelapukan dari ringan (1) hingga sempurna (5); kedalaman tanah dari sangat tipis (1) hingga sangat tebal (5); kelas struktur tanah dari horisontal (1) hingga miring pada perlapisan lunak (5); dan kelas tekstur tanah dari geluh (1) hingga lempung
(5). Akhirnya tingkat bahaya longsor tanah selanjutnya diklasifikasikan berdasarkan total harkat dari parameter penyebab dan pemicu longsor tanah. Adapun total klasifikasi Kelas Bahaya Longsor Tanah disajikan pada Tabel 2.

Langkah selanjutnya adalah menganalisis kejadian longsor secara deskriptif pada bagian-bagian lereng dengan bantuan analisis DEM (digital elevation modelling) untuk memperoleh gambaran tiga dimensi sehingga secara jelas kita dapat mengkaji mekanisme proses longsoran pada suatu penggal lereng. Posisi lereng dan bentuk lereng seperti apa kejadian longsor itu terjadi, demikian pula analisis terhadap morfostruktur lerengnya. Dengan mengetahui pola kejadian yang ada, diharapkan dapat memprediksi adanya pengulangan kejadian longsor dengan tipe dan kondisi lereng yang sama mendatang. Sasaran penelitian dasar ini adalah pengembangan konsepsi dasar geomorfologi analitik untuk kajian terjadinya longsoran. 
Tabel 2. Tingkat Bahaya Longsor Tanah

\begin{tabular}{|c|l|c|}
\hline No & \multicolumn{1}{|c|}{ Tingkat Bahaya Longsor } & Skor Total \\
\hline 1 & Sangat Rendah & $24-43,2$ \\
\hline 2 & Rendah & $>43,2-62,4$ \\
\hline 3 & Sedang & $>62,4-81,6$ \\
\hline 4 & Tinggi & $>81,6-100,8$ \\
\hline 5 & Sangat Tinggi & $>100,8-120$ \\
\hline
\end{tabular}

Sumber : hasil analisis

\section{HASIL DAN PEMBAHASAN}

Secara geografis letak daerah penelitian ini adalah $109^{\circ} 38^{\prime} 10^{\prime \prime}$ BT $109^{\circ} 43^{\prime} 30^{\prime \prime}$ BT dan $07^{\circ} 17^{\prime} 00^{\prime \prime}$ LS dan $07^{0} 23^{\prime} 50^{\prime \prime}$ LS. Berdasarkan data curah hujan daerah penelitian memiliki hujan tahunan sebesar $3631,9 \mathrm{~mm} /$ th dengan curah hujan bulanan rerata minimum sebesar 58,7 mm yang terjadi pada bulan Agustus dan curah hujan bulanan rerata maksimum sebesar 514,9 mm terjadi pada bulan Nopember, mempunyai 9 bulan basah, 2 bulan lembab, dan 1 bulan kering. Daerah penelitian mempunyai nilai $Q$ sebesar 0,111 atau bertipe A (sangat basah). Hal tersebut juga ditunjukkan bahwa di daerah penelitian rerata terjadi 16,42 hari hujan dalam satu bulan dengan curah hujan maksimum rerata sebesar $74,51 \mathrm{~mm}$. Kejadian hari hujan tertinggi terjadi pada bulan Nopember hingga Januari (20,2 hari) dengan curah hujan maksimum setiap kali kejadian hujan tertinggi pula $(94,1 \mathrm{~mm})$, sehingga pada bulan Januari kemungkinan terjadi longsor tanah sangat besar setelah 2 bulan sebelumnya terjadi curah hujan dengan intensitas yang tinggi dengan kejadian hujan yang hampir tiap hari terjadi. Adapun temperatur di daerah penelitian dengan ketinggian $271-1244 \mathrm{~m}$ dpal mempunyai suhu rerata $23^{\circ} \mathrm{C}$.
Daerah penelitian didominasi oleh lereng miring hingga sangat curam dengan kemiringan lereng $>15 \%$ dengan luas 40.309 ha atau sebesar $77,52 \%$ dari keseluruhan luas daerah penelitian. Daerah dengan morfologi datar hingga landai dengan kemiringan lereng lebih besar $0-3 \%$ dan $>3-8 \%$ hanya terdapat seluas 11.687 ha atau sebesar $22,48 \%$ dari keseluruhan luas daerah penelitian. Titik tertinggi sebesar $1.244 \mathrm{~m}$ dpal terdapat pada bagian tengah daerah penelitian yang merupakan puncak Gunung Pawinihan, dan titik terendah sebesar $271 \mathrm{~m}$ dpal yang terdapat di sisi selatan yang berbatasan dengan Sungai Serayu.

Mengacu pendapat Bemmelen (1949 dalam Imam Hardjono,1997), daerah penelitian secara keseluruhan terletak pada zone pegunungan Serayu Utara bagian tengah, dicirikan struktur lipatan, patahan, dan volkanisme disertai proses penurunan pada zaman Miosen. Akibatnya, terbentuk beberapa Formasi batuan berlapis seperti Formasi Merawu, Bodas, Ligung, dan Jembangan. Lebih lanjut Bemmelen menyatakan bahwa pembentukan Formasi Bodas diawali diendapkannya lapisan batugamping basal pada cekungan sedimentasi yang menurun secara cepat "selaras" dengan terjadinya pengangkatan Pegunungan 
Serayu Selatan. Setelah pengendapan bagian atas berakhir, diperkirakan akibat adanya tenaga endogen terjadi lagi fase tektonik Plio-Pleistosen yang ditandai dengan pengangkatan, perlipatan, dan persesaran disertai aktifitas volkanisme yang berulang-ulang. Sejarah geologi tersebut diperlukan dalam menganalisis pentingnya pengetahuan morfostruktur batuan pada suatu lereng terhadap kejadian bencana longsor di daerah penelitian.

Selanjutnya karakteristik litologi daerah penelitian akan berdampak terhadap proses pelapukan yang ada. Perbedaan kondisi litologi merupakan salah satu faktor yang menyebabkan perbedaan tingkat perkembangan lembah, baik pola lembah maupun kerapatan lembah. Daerah yang memiliki batuan resisten akan memiliki kecenderungan proses denudasional yang rendah, sehingga perkembangan lembah dan proses longsoran juga rendah. Litologi daerah penelitian didominasi lava andesit, batuan klastika gunungapi, dan breksi volkanik. Batuan tersebut mempunyai tingkat pelapukan yang tinggi dengan struktur perlapisan yang sejajar arah kemiringan lereng sehingga memungkinkan sekali lereng daerah penelitian rawan terjadi longsor tanah.

Kondisi geomorfologi daerah penelitian dipengaruhi aktivitas volkanik sehingga secara geomorfologis termasuk bentukan asal volkan. Pada beberapa tempat terdapat struktur sesar yang telah terdenudasi. Proses denudasi yang terjadi di daerah penelitian terutama disebabkan oleh kondisi iklim setempat baik input hujan maupun fluktuasi temperatur, kerja air dan gaya gravitasi. Beberapa proses eksogen yang terjadi di daerah penelitian antara lain adalah proses pelapukan, erosi dan long- soran. Proses pelapukan yang terjadi cukup intensif terutama pelapukan mekanis yang menghasilkan bahan induk tanah. Proses pelapukan yang terjadi banyak ditemukan pada batuan lava andesit dan breksi gunungapi yang tersingkap. Pelapukan tersebut mengakibatkan pengelupasan mengulit bawang yang disebut sebagai sphereodal weathering. Keberadaan kekar-kekar minor yang banyak terdapat pada batuan andesit dengan arah tidak beraturan mengakibatkan batuan mudah lapuk dan fragmen batuan mudah lepas dari semen pengikatnya. Dari hasil aktivitas proses tersebut, bentuklahan secara rinci disajikan pada Tabel 3.

Ada tiga macam tanah yang ada di daerah penelitian, yaitu Tropudalf (Latosol Coklat), Eutropept (Latosol Coklat Kekelabuan), dan Troporthent (Litosol). Jenis tanah tersebut berkembang dari batuan induk tuf dan breksi andesitis, sifat tanah umumnya mempunyai tekstur geluh lempungan, struktur remah-gumpal, konsistensi gembur hingga sangat gembur, $\mathrm{pH}$ 5,5- 6,0, permeabilitas bervariasi dari sangat lambat hingga cepat, kepekaan erosi tinggi, kandungan bahan organik relatif tinggi, dan kedalaman efektif tipis hingga relatif tebal $(24-120 \mathrm{~cm})$. Berdasarkan sebaran penggunaan lahan didominasi oleh tegalan seluas 2.323,69 (56,34\%) sehingga berisiko terhadap keberadaan longsoran yang terjadi. Kondisi kependudukan di daerah penelitian bahwa penduduk Kecamatan Banjarmangu 54,6\% bekerja pada sektor pertanian. Keadaan tersebut menghendaki pentingnya pendampingan oleh pemerintah daerah kepada penduduk dalam usaha pertanian yang konservatif.

Hasil pengharkatan dari 7 parameter yang mempengaruhi longsoran sebagaimana telah terdeskripsikan di atas dan 
Tabel 3. Bentuklahan Daerah Penelitian

\begin{tabular}{|c|l|l|r|r|}
\hline No. & $\begin{array}{c}\text { Simbol } \\
\text { Bentuklahan }\end{array}$ & \multicolumn{1}{|c|}{ Nama Bentuklahan } & $\begin{array}{c}\text { Luas } \\
\text { (ha) }\end{array}$ & \multicolumn{1}{|c|}{$\begin{array}{c}\text { Prosentase } \\
\text { Luas }\end{array}$} \\
\hline 1. & V8.SR & Dataran fluvial gunungapi tertoreh sangat ringan & 686,71 & 16,65 \\
\hline 2. & V13.R & Dataran gunungapi tertoreh ringan & 314,69 & 7,63 \\
\hline 3. & V19.B & Lereng pegunungan gunungapi tertoreh berat & 894,17 & 21,68 \\
\hline 4. & V19.S & Lereng pegunungan gunungapi tertoreh sedang & $1.355,28$ & 32,86 \\
\hline 5. & V19.R & Lereng pegunungan gunungapi tertoreh ringan & 163,74 & 3,97 \\
\hline 6. & V21.B & Pegunungan sumbat gunungapi tertoreh berat & 153,84 & 3,73 \\
\hline 7. & V24.SB & Pegunungan intrusi dike tertoreh sangat berat & 317,99 & 7,71 \\
\hline 8. & V24.B & Pegunungan intrusi dike tertoreh berat & 207,05 & 5,02 \\
\hline 9. & V24.S & Pegunungan intrusi dike tertoreh sedang & 30,93 & 0,75 \\
\hline & & Total Luas & $4.124,40$ & $100 \%$ \\
\hline
\end{tabular}

Sumber : hasil analisis peta bentuklahan, 2007

sesuai metode penelitian yang digunakan disajikan pada Tabel 4. berikut. Selanjutnya tingkat bahaya longsor tanah daerah penelitian disajikan dalam Tabel 5. dan disajikan dalam Peta tingkat bahaya longsor tanah berikut. Sementara deskripsi lokasi kejadian longsor disajikan dalam Lampiran penelitian ini.

Dari analisis Tabel 4 dan Tabel 5 berikut menunjukkan bahwa semakin besar harkat kemiringan lereng, pelapukan batuan, struktur perlapisan batuan, dan tekstur tanah menunjukkan tingkat bahaya longsor tanah yang semakin tinggi pula. Penggunaan lahan dengan harkat lebih besar belum tentu menyebabkan tingkat bahaya longsor tanah yang tinggi, hal itu tampak pada satuan bentuklahan V24.B dan V24.SB dengan harkat penggunaan lahan 3 justru tingkat bahaya longsornya lebih tinggi dibandingkan pada V21.B dengan harkat penggunaan lahan 4. Demikian pula pada kedalaman tanah dengan harkat 5 menghasilkan tingkat bahaya longsor tanah yang tinggi dan sangat tinggi, sementara kedalaman tanah dengan harkat 3 juga menunjukkan tingkat bahaya longsor yang tinggi.

Dari 9 satuan bentuklahan di atas ternyata ada 26 kejadian longsor yang bisa teridentifikasi dari hasil wawancara penduduk dan survei lapangan. Hasil pengamatan lapangan pada setiap lokasi longsoran, ternyata faktor-faktor yang menyebabkan suatu longsoran di setiap bentuklahan adalah bersifat khas dan tidak sama faktor pemicunya walaupun tipe longsorannya sama. Generalisasi atas faktor penyebab, pengaruh, dan pemicu suatu longsoran tidak sepenuhnya dapat tepat menggambarkan persebaran longsor yang senyatanya. Analisis longsoran di daerah penelitian didasarkan atas pemahaman proses longsoran yang disebabkan oleh bekerjanya gaya gravitasi pada material batuan dan atau tanah yang terletak pada posisi ketinggian tertentu. Di lapangan, material yang cenderung mengalami proses pelongsoran adalah material yang terletak pada sudut lereng tertentu. Pengamatan di lapangan 
Tabel 4. Pengharkatan dan Pembobotan Parameter yang Mempengaruhi Longsor Tanah

\begin{tabular}{|c|c|c|c|c|c|c|c|c|}
\hline $\begin{array}{c}\text { Bentuk- } \\
\text { lahan }\end{array}$ & $\begin{array}{c}\text { Kem. } \\
\text { Lereng } \\
(10 \mathrm{X})\end{array}$ & $\begin{array}{c}\text { Hujan } \\
(5,6 \mathrm{X})\end{array}$ & $\begin{array}{c}\text { Pengg. } \\
\text { Lahan } \\
(2,4 \mathrm{X})\end{array}$ & $\begin{array}{c}\text { Pel. } \\
\text { Batuan } \\
(4,2 \mathrm{X})\end{array}$ & $\begin{array}{c}\text { Struktur } \\
\text { Perl.batuan } \\
(0,54 \mathrm{X})\end{array}$ & $\begin{array}{c}\text { Tekstur } \\
\text { Tanah } \\
(0,36 \mathrm{X})\end{array}$ & $\begin{array}{c}\text { Kedalaman } \\
\text { Tanah } \\
(0.9 \mathrm{X})\end{array}$ & $\begin{array}{c}\text { Total } \\
\text { HarkatX } \\
\text { Konstanta }\end{array}$ \\
\hline V8.SR & 1 & 4 & 2 & 1 & 1 & 1 & 1 & 43,2 \\
\hline V13.R & 2 & 4 & 2 & 2 & 1 & 2 & 2 & 58,66 \\
\hline V19.B & 3 & 4 & 3 & 5 & 3 & 3 & 3 & 86 \\
\hline V19.S & 3 & 4 & 3 & 3 & 3 & 3 & 3 & 77,60 \\
\hline V19.R & 4 & 4 & 2 & 2 & 3 & 3 & 3 & 81,0 \\
\hline V21.B & 4 & 4 & 4 & 4 & 4 & 4 & 5 & 96,9 \\
\hline V24.SB & 5 & 4 & 3 & 5 & 5 & 4 & 5 & 108,24 \\
\hline V24.B & 5 & 4 & 3 & 4 & 5 & 4 & 5 & 104,04 \\
\hline V24.S & 4 & 4 & 3 & 2 & 2 & 2 & 2 & 81,6 \\
\hline
\end{tabular}

Sumber: Analisis data parameter longsor tanah

Tabel 5. Sebaran Kelas-Kelas Bahaya Longsoran di Daerah Penelitan

\begin{tabular}{|r|c|c|c|c|}
\hline No & Bentuklahan & Tingkat Bahaya & Luas (ha) & \% Luas \\
\hline 1. & V8.SR & Sangat Rendah & 686,71 & 16,65 \\
\hline 2. & V13.R & Rendah & 314,69 & 7,63 \\
\hline 3. & V19.B & Tinggi & 894,17 & 21,68 \\
\hline 4. & V19.S & Sedang & $1.355,28$ & 32,86 \\
\hline 5. & V19.R & Sedang & 163,74 & 3,97 \\
\hline 6. & V21.B & Tinggi & 153,84 & 3,73 \\
\hline 7. & V24.SB & Sangat Tinggi & 317,99 & 7,71 \\
\hline 8. & V24.B & Sangat Tinggi & 207,04 & 5,02 \\
\hline 9. & V24.S & Sedang & 30,93 & 0,75 \\
\hline \multicolumn{2}{|c|}{ Total Luas : } & $4.124,40$ & 100.00 \\
\hline
\end{tabular}

Sumber : hasil analisis peta bahaya longsoran tanah

menunjukkan bahwa faktor morfometri lereng dan morfostruktur batuan dan tanah sangat mempengaruhi apakah suatu daerah itu rawan longsor atau tidak.

Faktor batuan yang mempengaruhi tingkat kerawanan longsor tidak hanya mencakup jenis dan kekerasan batuan saja, tetapi yang lebih penting adalah struktur batuannya. Batuan yang berlapis miring searah dengan arah sudut lereng akan mempunyai tingkat kerawanan yang tinggi. Batuan yang keras dan masih relatif segar dapat juga menjadi rawan longsor apabila dia mempunyai banyak retakan/joint yang searah dengan arah sudut lereng. Batuan yang keras dan banyak joint tersebut akan menjadi lebih rawan lagi apabila menum- 
pang di atas batuan lunak yang mempunyai sifat kembang kerut. Daerah dengan tanah yang tebal dan terletak pada topografi tinggi juga relatif rawan terhadap longsoran karena daerah ini sangat potensial untuk mengalami penambahan beban massa karena tanah umumnya mempunyai kemampuan menyerap air hujan yang relatif tinggi dibandingkan dengan batuan. Atas dasar pengertian tersebut, maka penilaian kerawanan longsor didasarkan pada penilaian atas parameter morfometri lereng dan morfostruktur lereng.

Kondisi lapisan tanah/batuan pada lereng-lereng di daerah penelitian umumnya berupa tanah residual yang berpermeabilitas relatif tinggi dengan tebal kira-kira 3 - 6 m di permukaan dan didasari oleh lapisan keras batuan breksi. Bentuk bidang gelincir setelah longsor termasuk tipe bidang gelincir datar, dan terjadi pada lokasi di sekitar pertemuan antara lapisan tanah di bagian atas dan lapisan tanah keras atau batuan di bagian bawah.

Secara morfometri lereng, titik kejadian longsor terbanyak pada lereng tengah pegunungan (11), lereng bawah (9), dan pada lereng atas (5). Tipe aliran, jatuhan tanah, dan jatuhan batu semuanya terjadi pada lereng atas, tipe longsoran dominan $(80 \%)$ terjadi pada lereng bawah, sedangkan tipe nendatan terdapat pada lereng atas, tengah dan bawah. Dari aspek bentuk lereng 70\% kejadian longsor terdapat pada posisi lereng yang cekung dan klas lereng 3 - $5(>9 \%)$. Dari aspek morfostruktur daerah penelitian mempunyai batuan yang hampir sama karakteristiknya yakni dicerminkan oleh tingkat pelapukan dan kondisi struktur batuan yang relatif sama yang rawan terjadi bencana longsor. Kondisi lereng yang cekung dan miring menjadi titik konsentrasi aliran air permukaan dan bawah permukaan yang besar yang diperkirakan menjadi faktor paling menentukan terjadinya longsoran.

Dari analisis tabel hasil pengharkatan terhadap parameter pemicu terjadinya longsoran tanah, menunjukkan bahwa semakin besar harkat kemiringan lereng, solum tanah, tingkat pelapukan batuan, struktur perlapisan batuan, adanya kekar, rembesan air, dan pemotongan lereng menunjukkan tingkat bahaya longsor tanah yang semakin tinggi. Kondisi tekstur tanah, permeabilitas, drainase, dan penggunaan lahan dengan harkat lebih besar belum tentu tingkat bahaya longsor tanahnya lebih tinggi. Dari hasil pengamatan lapangan pada setiap lokasi longsoran, faktor-faktor yang menyebabkan suatu longsoran dapat terjadi ternyata bersifat khas dan tidak sama faktor pemicunya walaupun tipe longsorannya sama, namun frekuensi kejadian longsoran bertambah dengan bertambahnya kemiringan lereng, solum tanah, tingkat pelapukan, struktur perlapisan, adanya kekar dan rembesan, dan pemotongan lereng sehingga model konservasi harus mengacu pada parameter.

\section{KESIMPULAN DAN SARAN}

Daerah penelitian terdapat 9 satuan bentuklahan dengan 5 tingkat bahaya longsor tanah. Tingkat bahaya longsor tanah sangat rendah terdapat pada satuan bentuklahan Dataran fluvial gunungapi tertoreh sangat ringan (V8.SR) seluas 686,71 ha (16,65\% luas seluruh daerah penelitian). Tingkat bahaya longsor tanah rendah terdapat pada satuan bentuklahan Dataran gunungapi tertoreh ringan (V13.R) seluas 314,69 ha $(7,63 \%)$. Tingkat bahaya longsor tanah sedang terdapat pada 3 satuan 
bentuklahan Lereng pegunungan gunungapi tertoreh sedang (V19.S), Lereng gunungapi tertoreh ringan (V19.R), dan Pegunungan intrusi dike tertoreh sedang (V24.S) dengan luas total $1.549,95$ ha $(37,58 \%)$. Tingkat bahaya longsor tinggi terdapat pada Lereng pegunungan gunungapi tertoreh berat dan Pegunungan sumbat gunungapi tertoreh berat dengan total $1.048,01$ ha $(25,41 \%)$. Tingkat bahaya longsor sangat tinggi pada Pegunungan intrusi dike tertoreh sangat berat dan Pegunungan intrusi dike tertoreh berat seluas 525,04 (12,73\%).

Kejadian longsor tertinggi terjadi pada bentuklahan dengan Tingkat bahaya sangat tinggi yakni sebanyak 13 kejadian, selanjutnya pada tingkat bahaya tinggi sebanyak 8 , tingkat bahaya sedang ada 4 kejadian, dan tingkat bahaya longsor rendah ada 3 kejadian. Ada 2 satuan bentuklahan yang sama sekali tidak dijumpai kejadian longsor (V13.R dan V8.SR). Kejadian longsor terbanyak bertipe longsor (10), nendatan (8), aliran (5), jatuhan batu (2), dan jatuhan tanah (1).

Rekomendasi penanganan daerah longsor perlu memperhatikan proses-proses penyebab proses-proses penyebab longsoran. Beberapa kasus longsoran yang terjadi di daerah penelitan terjadi di daerah yang telah dikonservasi secara baik atas dasar pandangan pengendalian erosi tanah. Pemicu pada longsoran pada lahan yang telah dikonservasi dengan baik salah satunya adalah erosi parit pada saluran pembuang. Hal lain adalah penambahan beban massa karena teras dapat juga berfungsi sebagai penampung air sehingga tanah dalam keadaan jenuh. Tanah dan material tanah yang dalam kondisi jenuh air mempunyai berat yang jauh lebih tinggi dibandingkan dengan tanah kering, oleh karena itu risiko longsoran menjadi meningkat.

Penguatan sisi-sisi parit erosi agar tidak longsor disarankan untuk daerahdaerah yang telah teridentifikasi mempunyai tingkat erosi tanah lanjut. Hal ini ditujukan agar tidak terjadi tebing ambrol yang dapat menyumbat parit dan membendung aliran yang ada padanya. Penguatan dasar parit erosi juga perlu dilakukan agar parit tidak berkembang menjadi parit yang dalam. Pendalaman parit dapat dipandang sebagai mempertajam lereng di sisi kanan kiri parit yang berarti menambah risiko terjadi longsoran. Pemberian material kasar berupa batu-batu juga disarankan agar aliran air di dalam parit dapat tetap mengalir tetapi tidak dengan kecepatan aliran yang erosif. Metode ini sering dikenal dengan gully plug.

\section{UCAPAN TERIMAKASIH}

Tulisan ini merupakan hasil penelitian dasar yang dilaksanakan atas biaya Dirjen Pendidikan Tinggi Departemen Pendidikan Nasional No. 156/SP2H/PP/ DP2M/2007, tanggal 29 Maret 2007. Terima kasih disampaikan kepada Rektor UMS cq. Kepada Prof. Dr. Markhamah, M.Hum selaku Kepala Lembaga Penelitian dan Pengabdian Masyarakat yang telah memberikan kesempatan kepada penulis untuk melakukan penelitian ini. Terima kasih disampaikan kepada Drs.Yuli Priyana, M.Si selaku Dekan Fakultas Geografi UMS yang telah memberi ijin melakukan penelitian ini, kepada Mas Rozak atas bantuan analisis citra Landsat dan sistem informasi geografisnya. Terima kasih juga saya ucapkan kepada Imam Mustofa atas bantuan survei lapangannya, semoga segera memperoleh pekerjaan untuk menerapkan ilmu Geografi ini. 


\section{DAFTAR PUSTAKA}

American Planning Association, Landslides Research, bttp://www.planning.org / landslides/ docs/main.html, 1/26/2006.

Burhanudin, 2006, Longsor Banjarnegara, Faktor Alam atau Kesalahan Manusia?, Harian Kompas, 11 Januari 2006, Jakarta: Penerbit Gramadia Group.

David, J.Rogers, Recent Developments in Landslide Mitigation Techniques, http:/ / anaheimlandslide.com/developments.htm., 1/27/2006

Dwikorita Karnawati, 2002, Pengenalan Daerah Rentan Gerakan Tanah dan Upaya Mitigasinya, Makalah Seminar Nasional Mitigasi Bencana Alam Tanah Longsor, Semarang 11 April 2002, Semarang: Pusat Studi Kebumian Lembaga Penelitian Universitas Diponegoro.

Goudie, Andrew,S., 1981, Geomorphological Tecniques, London: George Allen \& Unwin.

Imam Hardjono, 1997, Penggunaan Foto Udara Pankromatik Hitam Putih Untuk Kajian Gerakan Massa di Daerah Karangkobar dan Sekitarnya, Banjarnegara, Jawa Tengah, Tesis- S2, Yogyakarta: Program Pasca Sarjana UGM.

Junun Sartohadi dan Rina Purwaningsih, 2004, Korelasi Spasial Antara Tingkat Perkembangan Tanah dengan Tingkat Kerawanan Gerakan Massa di DAS Kayangan Kabupaten Kulon Progo Daerah Istimewa Yogyakarta, Forum Geografi, Vol.18, No.1, 2004. Hlm.14-31.

Kabul Basah Suryolelono, 2002, Bencana Alam Tanah Longsor Perspektif Ilmu Geoteknik, Pidato Pengukuhan Jabatan Guru Besar, Yogyakarta: Fakultas Teknik UGM.

Kuswaji Dwi Priyono, Yuli Priyana, dan Priyono. 2006. "Analisis Tingkat Bahaya Longsor Lahan di Kecamatan Banjarmangu Kabupaten Banjarnegara”. Forum Geografi, Vol. 20, No. 2, Desember 2006. Hlm. 175-189.

Ritter, Dale F., ad.el., 1995. Geomorphology Process and Landforms. Dubuque IA: Brown Communication Inc.

Sunarto Goenadi, dkk., 2003, Konservasi Lahan Terpadu Daerah Rawan Bencana Longsoran di Kabupaten Kulonprogo Daerah Istimewa Yogyakarta, Laporan Penelitian, Yogyakarta: Lembaga Penelitian UGM.

Sutikno, dkk., 2001, Pengelolaan Data Spasial Untuk Penyusunan Sistem Informasi Penanggulangan Tanah Longsor di kabupaten Kulon Progo, Daerah Istimewa Yogyakarta, Makalah Seminar Dies Fakultas Geografi UGM ke-38 Tanggal 29 Agustus 2001, Yogyakarta: Fakultas Geografi UGM

Zuidam, R.A. \& Zuidam Cancelado, F.I.,1979, Terrain Analysis and Classification Using Areal Photographs, A Geomorphologycal Approach, Netherland, Enschede: ITC 


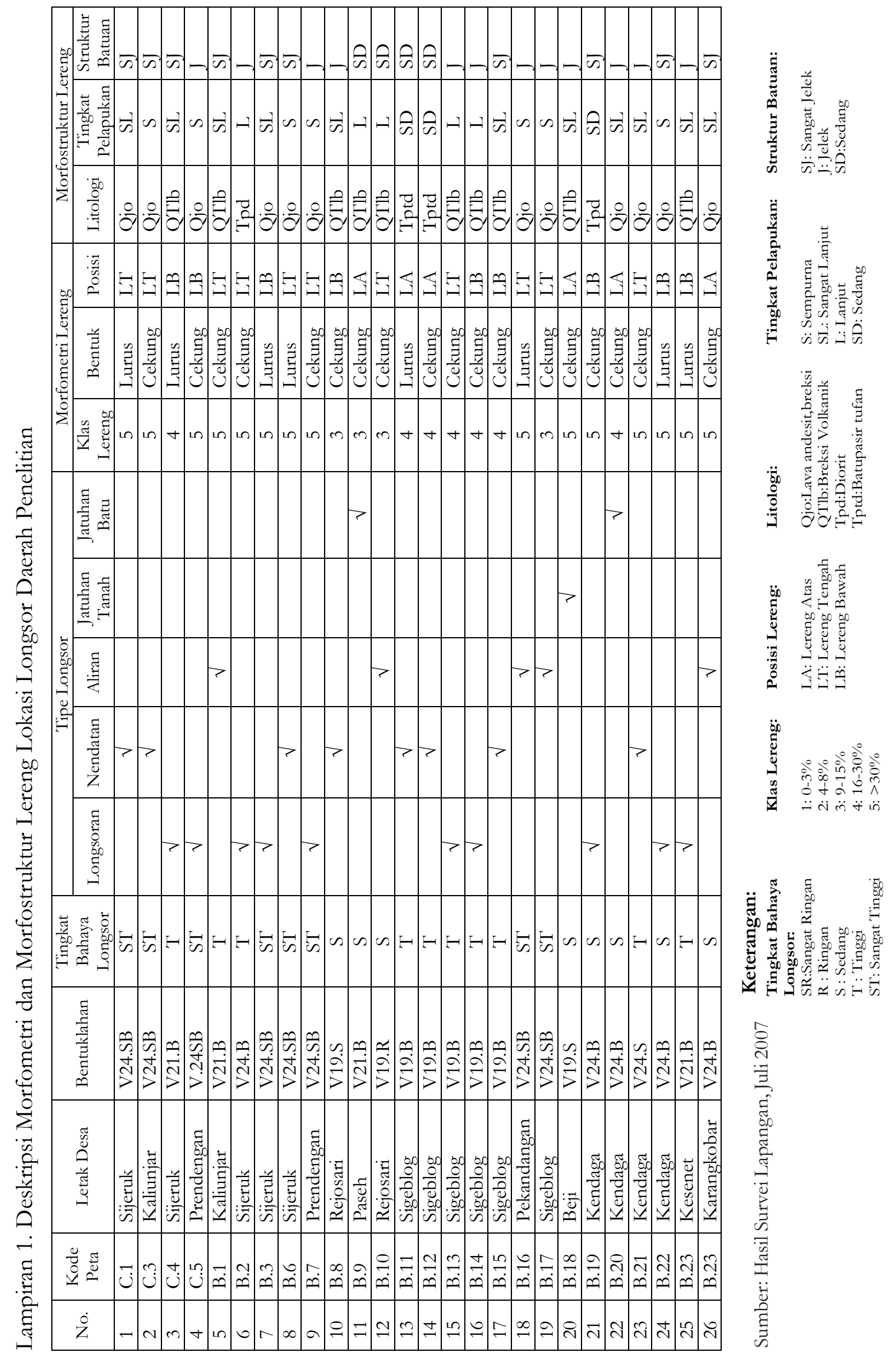




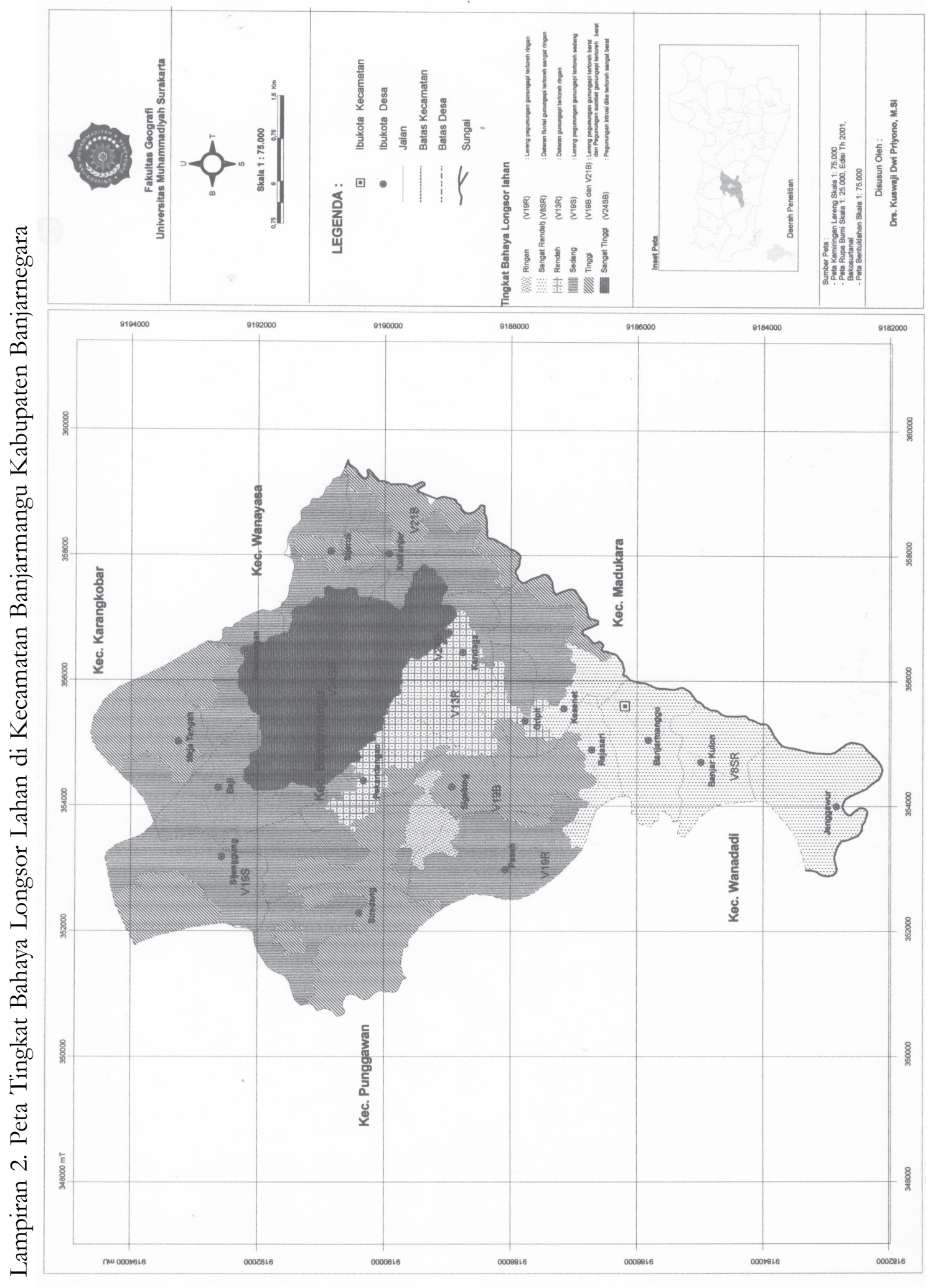




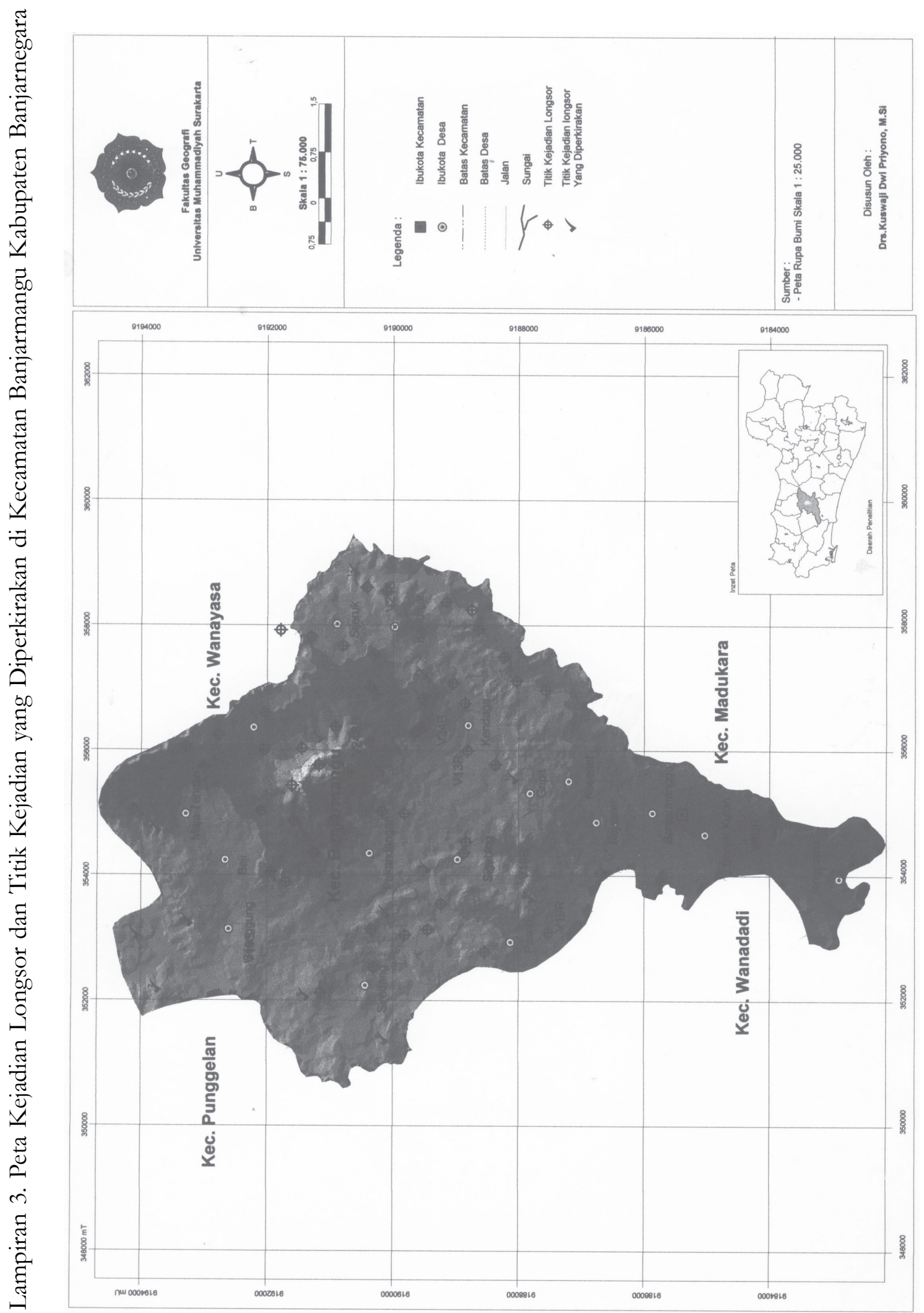

